\title{
Spoligotyping and variable number tandem repeat analysis of Mycobacterium bovis isolates from cattle in Brazil
}

\author{
Patrícia Martins Parreiras ${ }^{1}$, Giovanna Ivo Andrade², Telma de Figueiredo do Nascimento ${ }^{3}$, \\ Maraníbia Cardoso Oelemann ${ }^{3}$, Harrison Magdinier Gomes ${ }^{3}$, Andrea Padilha de Alencar ${ }^{4}$, \\ Ronnie Antunes de Assis ${ }^{4}$, Pedro Moacyr Pinto Coelho Mota ${ }^{4}$, Márcia Aparecida da Silva Pereira ${ }^{3}$, \\ Francisco Carlos Faria Lobato ${ }^{5}$, Andrey Pereira Lage 2 , Philip Noel Suffys ${ }^{3 /+}$
}

\begin{abstract}
${ }^{1}$ Instituto René Rachou-Fiocruz, Belo Horizonte, MG, Brasil ${ }^{2}$ Laboratório de Bacteriologia Aplicada ${ }^{5}$ Laboratório de Bacterioses e Pesquisa, Departamento de Medicina Veterinária Preventiva, Escola de Veterinária, Universidade Federal de Minas Gerais, Belo Horizonte, MG, Brasil ${ }^{3}$ Laboratório de Biologia Molecular Aplicada a Micobactérias, Instituto Oswaldo Cruz-Fiocruz, Av. Brasil 4365, 21040-360 Rio de Janeiro, RJ, Brasil ${ }^{4}$ Laboratório Nacional Agropecuário de Minas Gerais, Pedro Leopoldo, MG, Brasil
\end{abstract}

We performed spoligotyping and 12-mycobacterial interspersed repetitive unit-variable number tandem repeats (MIRU-VNTRs) typing to characterise Mycobacterium bovis isolates collected from tissue samples of bovines with lesions suggestive for tuberculosis during slaughter inspection procedures in abattoirs in Brazil. High-quality genotypes were obtained with both procedures for 61 isolates that were obtained from 185 bovine tissue samples and all of these isolates were identified as $\mathrm{M}$. bovis by conventional identification procedures. On the basis of the spoligotyping, 53 isolates were grouped into nine clusters and the remaining eight isolates were unique types, resulting in 17 spoligotypes. The majority of the Brazilian M. bovis isolates displayed spoligotype patterns that have been previously observed in strains isolated from cattle in other countries. MIRU-VNTR typing produced 16 distinct genotypes, with 53 isolates forming eight of the groups, and individual isolates with unique VNTR profiles forming the remaining eight groups. The allelic diversity of each VNTR locus was calculated and only two of the 12-MIRU-VNTR loci presented scores with either a moderate (0.4, MIRU16) or high (0.6, MIRU26) discriminatory index (h). Both typing methods produced similar discriminatory indexes (spoligotyping $h=0.85$; MIRU-VNTR $h=0.86$ ) and the combination of the two methods increased the $h$ value to 0.94 , resulting in 29 distinct patterns. These results confirm that spoligotyping and VNTR analysis are valuable tools for studying the molecular epidemiology of M. bovis infections in Brazil.

Key words: Mycobacterium bovis - spoligotyping - MIRU-VNTR typing - bovine tuberculosis - molecular epidemiology

Mycobacterium bovis is the major causative agent of bovine tuberculosis (TB) and one of the species of the Mycobacterium tuberculosis Complex (MTBC), a group of very closely related Mycobacterium species. M. bovis is usually isolated from domestic cattle, but also infects a range of mammalian species, including humans. Human TB is primarily caused by $M$. tuberculosis infections, but diseases caused by $M$. bovis infections have been reported and represent a public health concern (Cosivi et al. 1998, Smith et al. 2006).

Bovine TB is distributed in cattle throughout the world and, according to the disease timelines available in the Worldwide Animal Health Information Database (OIE 2010), 109 countries reported the presence of $M$. bovis infections and/or clinical diseases in their cattle herds at some time from 2005-2010. Bovine TB was con-

Financial support: CNPq, CAPES, FAPEMIG, FEPMVZ/EV-UFMG, PAPES-FIOCRUZ-RJ

PMP and GIA contributed equally to this work. GIA is CAPES ProDoc fellowship recipient.

+ Corresponding author: psuffys@ioc.fiocruz.br

Received 10 April 2011

Accepted 8 November 2011 sidered eradicated in most developed countries that have a tradition of cattle farming and the prevalence of the disease has reached very low levels in these countries as a result of severe control policies. In contrast, in developing countries with recently implanted control measures, considerable economic losses consistently occur in regions with intense cattle breeding, such as Brazil and Argentina (Mota \& Lobato 1998).

To improve this situation in Brazil, the National Program for Eradication and Control of Bovine Brucellosis and Tuberculosis (PNCEBT) was created in 2001. Measures included the use of intradermal tuberculin tests (single cervical tuberculin test) as a standard diagnostic screening test and the comparative cervical tuberculin test for confirmation, in accordance with the international standards for the diagnosis of bovine TB (MAPA 2006).

Similar to recent developments in human TB research, $M$. bovis genotyping has contributed to a better knowledge of bovine TB transmission and could lead to improvements in the effective management of bovine TB control schemes. The most common epidemiological molecular typing methods for members of the MTBC are the insertion sequence 6110-based restriction fragment length polymorphism (IS6110-RFLP), the spacer oligonucleotide typing (spoligotyping) and the analysis of the copy number of mycobacterial interspersed repetitive unit-variable number tandem repeats (MIRU-VNTRs). 
While IS6110-RFLP lacks resolution in this species, spoligotyping has been demonstrated to be a fast and cost-effective method for first-line typing (Haddad et al. 2004). The MIRU-VNTR typing procedure has been extensively evaluated in $M$. tuberculosis and the recent data available about this method on M. bovis strains confirmed its considerable power of discrimination (Sola et al. 2003, Michel et al. 2008, 2010). Smith et al. (2006) inferred that a combination of spoligotyping and VNTR typing resulted in the simplest and most cost-effective method for routine molecular typing and epidemiological tracing of bovine TB in Great Britain.

Some previous studies have successfully employed techniques such as IS6110-RFLP and spoligotyping to genotype M. bovis strains isolated from cattle in Brazil (Zanini et al. 2001, 2005, Rodriguez et al. 2004), but as far as we know, no data exist on genotyping of $M$. bovis by combining spoligotyping and MIRU-VNTR typing in our country. We aimed to use spoligotyping and MIRU-VNTR typing to assess the genetic diversity of Brazilian M. bovis isolates.

\section{MATERIALS AND METHODS}

Sampling and conventional procedures - During 2001 and 2002, tissue samples from cattle with lesions suggestive of TB were collected immediately after slaughter at the time of inspection in abattoirs. The study samples were collected in abattoirs that followed slaughter inspection procedures from the states of Amazonas (AM), Paraíba (PB), Distrito Federal (DF), Mato Grosso do Sul (MS), São Paulo, Santa Catarina (SC) and Minas Gerais (MG). The sampled specimens from respective carcasses were pooled, put on ice and sent to the Laboratório Nacional Agropecuário de Minas Gerais (Pedro Leopoldo, $\mathrm{MG}$ ), where they were processed for inoculation in Stonebrink culture medium (Mota 1985). The cultures were incubated at $37^{\circ} \mathrm{C}$ and verified for bacterial growth every week for a period of at least two months. Bacterial isolates were submitted to standard procedures for differentiation of certain species of the MTBC, including the evaluation of niacin production, nitrate reductase activity, Tween hydrolysis, catalase activity at $68^{\circ} \mathrm{C}$ and resistance to pyrazinamide and 2-thiophenic acid (Wayne et al. 1974, 1976).

Spoligotyping - Nucleic acids were extracted from cultures with M. bovis according to Pitcher et al. (1989). The spoligotyping method was conducted as described by Kamerbeek et al. (1997). Amplification of the direct repeat (DR) region was performed in a total volume of $50 \mu \mathrm{L}$ with $0.2 \mathrm{mM}$ of each dNTP $(10 \mathrm{mM}$ Tris- $\mathrm{HCl}, \mathrm{pH}$ $8.0 ; 50 \mathrm{mM} \mathrm{KCl}), 1.5 \mathrm{mM} \mathrm{MgCl}, 20$ pmol of each primer (DRa and DRb biotin-labelled primers), $1 \mathrm{U}$ of Taq DNA polymerase and $10 \mathrm{ng}$ of DNA. The polymerase chain reaction (PCR) consisted of an initial denaturation of $96^{\circ} \mathrm{C}$ for $3 \mathrm{~min}, 20$ cycles of $96^{\circ} \mathrm{C}$ for $1 \mathrm{~min}, 55^{\circ} \mathrm{C}$ for $1 \mathrm{~min}$ and $72^{\circ} \mathrm{C}$ for $30 \mathrm{~s}$ followed by final extension at $72^{\circ} \mathrm{C}$ for 5 min. Pure DNA from M. bovis BCG Moureau and M. tuberculosis $\mathrm{H} 37 \mathrm{Rv}$ were used in the experiment as positive controls and ultra-pure water was used as a negative control. The PCR products were hybridised to a membrane (Isogen, The Netherlands) containing 43 oligonucleotides of known spacer sequences by reversed- line blot hybridisation. After incubating with streptavidin-peroxidase, the spacers were detected by enhanced chemiluminescence detection (ECL Detection kit, Amersham Pharmacia Biotech). Authoritative and unique names (SB numbers) to spoligotype patterns were assigned by Mbovis.org website (Smith \& Upton 2011).

MIRU-VNTR typing - The MIRU-VNTR analysis was performed by determining the VNTR copy number of the MIRU loci 2, 4, 10, 16, 20, 23, 24, 26, 27, 31, 39 and 40, according to method published by Supply et al. (2000). These PCRs were performed by adding $10 \mathrm{ng}$ of DNA to $25 \mu \mathrm{L}$ of a mixture of 100 pmol of specific primers for each locus, $0.2 \mathrm{mM}$ of each dNTP, $1 \mathrm{U}$ of Taq DNA polymerase, $1 \mathrm{X}$ PCR buffer and a final concentration of $\mathrm{MgCl}_{2}$ of $1 \mathrm{mM}$ (MIRUs 20 and 26), $1.5 \mathrm{mM}$ (MIRUs 16, 24 and 27), $2.5 \mathrm{mM}$ (MIRU 39) or $2 \mathrm{mM}$ (the remaining loci). Samples were subjected to $95^{\circ} \mathrm{C}$ for $5 \mathrm{~min}$, 40 cycles including $95^{\circ} \mathrm{C}$ for $1 \mathrm{~min}, 60^{\circ} \mathrm{C}$ for $1 \mathrm{~min}\left(55^{\circ} \mathrm{C}\right.$ for $1 \mathrm{~min}$ for MIRUs 24 and 26) and $72^{\circ} \mathrm{C}$ for $1.5 \mathrm{~min}$ with a final extension at $72^{\circ} \mathrm{C}$ for $10 \mathrm{~min}$. The fragment size of the PCR products was estimated by running them through a $2 \%$ agarose gel stained with ethidium bromide $(0.5 \mu \mathrm{g} / \mathrm{mL})$ and comparing them to a $100 \mathrm{bp}$ DNA ladder (Invitrogen, Life Technologies, Carlsbad, CA).

Allelic and genotypic diversity - The discriminatory index (h) was used to calculate the allelic diversity of each VNTR locus and to measure the genotypic diversity attained for each employed method taken individually or in combination to define genotypes (Hunter \& Gaston 1988).

Clustering analysis - Spoligotypes were converted to binary values and MIRU-VNTR profiles were expressed as numerical values by comparing to a table as described by Supply et al. (2000). These data were introduced into Excel tables and transferred into the Bionumerics package (version 5.1, Applied Maths, St-MartinLatem, Belgium). Spoligotypes and MIRU-VNTR profiles were recorded as character data and were analysed as a combined dataset using the categorical character option as a similarity/distance coefficient and the unweighted pairgrouping method analysis (UPGMA) algorithm to generate a dendrogram.

\section{RESULTS}

Sampling and conventional procedures - Presumptive growth of mycobacteria was observed in isolates from 89 of the 185 sampled animals (48.1\%). Conventional procedures conclusively identified 61 of these isolates $(69 \%)$, all of which were M. bovis. Of these 61 isolates, $49(80.3 \%)$ originated from MG and 12 (19.7\%) originated from other states. For four isolates, two from $\mathrm{SC}$ and two from MG, no information about the municipality of origin was available.

Spoligotyping - Complete spoligotypes were obtained from 61 isolates (Table I). In total, 17 different patterns were observed, nine of which formed clusters that included $53(86.8 \%)$ of the 61 isolates (designated by us as S1-S9), with the rest considered orphan patterns (13.2\%) (S10-S17) (Table I). All 17 patterns had been previously reported. The most frequently observed spo- 
ligotypes were SB0295 $(\mathrm{n}=18,29.5 \%)$ and SB0121 $(\mathrm{n}$ $=14,23 \%)$ and the frequency of the remaining patterns varied between $9.8 \%(\mathrm{n}=9)$ and $1.6 \%(\mathrm{n}=1)$ (Table I). The distribution of the spoligotypes according to geographic origin is presented in Fig. 1A.

MIRU-VNTR typing - We obtained 16 complete MIRU-VNTR genotypes from the 61 isolates that presented full spoligotype patterns (Table II). The VNTR types (designated by us as V1-V8) formed eight clusters composed of 53 different isolates and each of the remaining types (V9-V16) were composed of a single isolate. The VNTR types most frequently observed were V7 $(n=15,24.6 \%)$ and V4 $(n=14,23 \%)$ and the remaining types had frequencies varying between $11.5 \%(\mathrm{n}=$ 7) and $1.6 \%(\mathrm{n}=1)$. The geographic distribution of the M. bovis isolates according to their VNTR signatures is represented in Fig. 1B.

Allelic and genotypic diversity - The resolution power of each 12-MIRU locus was calculated using the diversity index of the alleles and is shown in Table III. The values of these allelic diversities differed considerably, ranging between 0-0.06 for MIRU loci 4, 10, 20, 23, 24, 39 and 40 and between 0.10-0.16 for MIRU loci 2, 27 and 31. Higher indexes were obtained for MIRU loci 16 $(0.43)$ and $26(0.65)$.

The data summarising the $\mathrm{h}$ obtained using both typing procedures are shown in Table IV. Spoligotyping and MIRU-VNTR typing rendered 17 and 16 different genotypes, respectively, and spoligotyping formed the largest cluster. Better discrimination was achieved when com- bining the two methods, resulting in a genotypic diversity of 0.94 and 29 distinct patterns that included 11 clusters formed by 43 isolates. The largest cluster was reduced to nine isolates, compared with 18 and 15 isolates from spoligotyping and MIRU typing, respectively. The resolution of the clusters formed by spoligotypes through VNTR typing and vice-versa are presented in Table V. Both procedures subdivided the groups defined by each method.

Clustering analysis - A dendrogram based on the composite data of spoligotyping and MIRU-VNTR typing was constructed using the UPGMA algorithm and the result is shown in Fig. 2. When clusters were defined to have $100 \%$ similarity, 43 isolates were grouped into 11 clusters (1 cluster each of 9, 8, 5 and 4 isolates, 3 clusters of 3 isolates and 4 clusters of 2 isolates) and 18 individual genotypes, as confirmed by the $\mathrm{h}$ values of the combined techniques. However, we were also interested in clusters formed by applying a less stringent definition for grouping.

Using a cut-off stringency of $85 \%$ similarity in the dendrogram, we observed four clusters (Fig. 2). Cluster I was composed of 4 MIRU types, including two (V2 and V9) with a corresponding SB0274 spoligotype, one (V16) with an isolate corresponding to SB0484 and one (V12) with an isolate characterised as SB1033 (V12). Cluster II included the MIRU types V5 and V11 and the spoligotypes SB0881 $(n=4)$, SB1145 $(n=2)$ and SB1806 $(\mathrm{n}=1)$. Cluster III was composed of three MIRU types (V2, V4 and V8), with V4 containing 14 isolates with spoligotypes SB0295, SB0121, SB0332, SB0337, V8 con-

TABLE I

International name, frequency and genotypic profile of the spoligotypes

\begin{tabular}{|c|c|c|c|}
\hline ID & Spoligotype pattern ${ }^{a}$ & $\begin{array}{c}\text { Isolates } \\
\mathrm{n}(\%)\end{array}$ & Spoligotype description ${ }^{b}$ \\
\hline S1 & SB0120 & $3(4.9)$ & 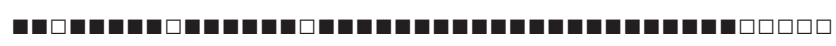 \\
\hline S2 & SB0121 & $14(23)$ & घg \\
\hline S3 & SB0295 & $18(29.5)$ & 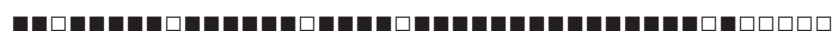 \\
\hline S4 & SB0881 & $4(6.6)$ & 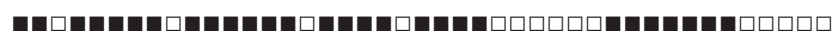 \\
\hline S5 & SB0274 & $6(9.8)$ & 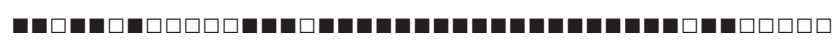 \\
\hline S6 & SB1802 & $2(3.3)$ & 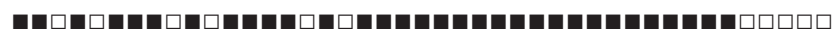 \\
\hline S7 & SB0134 & $2(3.3)$ & 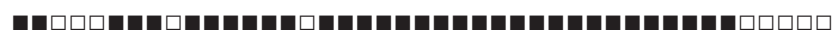 \\
\hline S8 & SB1055 & $2(3.3)$ & 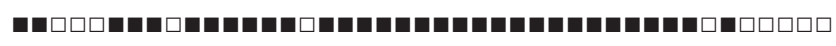 \\
\hline S9 & SB1145 & $2(3.3)$ & 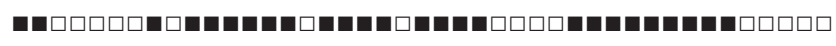 \\
\hline S10 & SB1806 & $1(1.6)$ & घg \\
\hline S11 & SB0332 & $1(1.6)$ & ตn \\
\hline S12 & SB1803 & $1(1.6)$ & 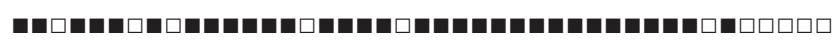 \\
\hline S13 & SB1033 & $1(1.6)$ & 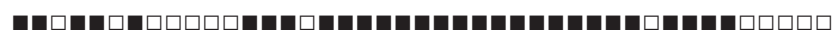 \\
\hline S14 & SB0337 & $1(1.6)$ & घh \\
\hline S15 & SB0267 & $1(1.6)$ & 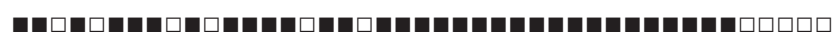 \\
\hline S16 & SB0484 & $1(1.6)$ & 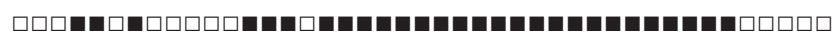 \\
\hline S17 & SB1136 & $1(1.6)$ & 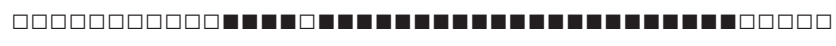 \\
\hline
\end{tabular}

$a$ : international name assigned by Mbovis.org; $b$ : the black and white boxes indicate the presence and absence, respectively, of the specific spacer at position 1-43 in the direct repeat locus. 
taining two isolates of SB0121 and V2 containing two isolates genotyped as SB0120 and SB0295. Cluster IV comprised eight MIRU types (V1, V3, V6, V7, V10, V13, V14 and V15), containing 28 isolates that were further defined by nine spoligotypes: SB0295, SB0121, SB0120, SB1055, SB0134, SB0267, SB1136, SB1802 and SB1803.

When using a cut-off value of approximately $80 \%$ similarity, two additional clusters were observed: group A, which included spoligotype patterns with spacer 6, but without spacers 8-12 (which are related to the ancestor pattern SB0140), and group B, which included patterns based on BCG-like spoligotypes (Fig. 2).

A

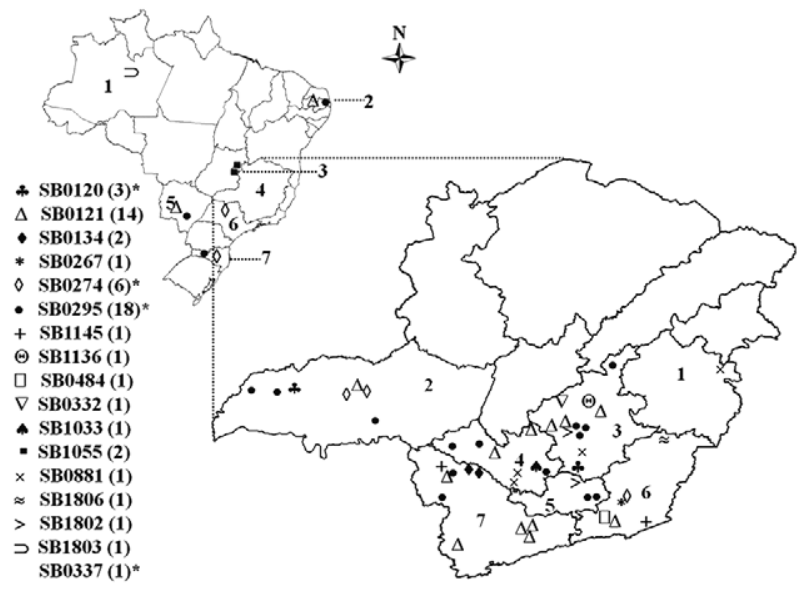

B

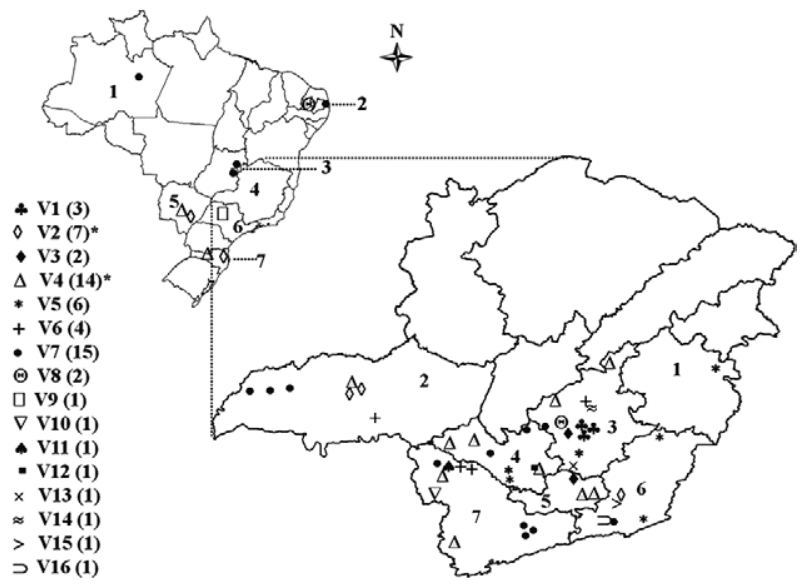

Fig. 1: geographical distribution of the spoligotype patterns (A) and mycobacterial interspersed repetitive unit-variable number tandem repeats (MIRU-VNTR) types (B) in the Brazilian states [(maps at the top and left) (1: Amazonas (AM); 2: Paraíba (PB); 3: Distrito Federal (DF); 4: Minas Gerais (MG); 5: Mato Grosso do Sul (MS); 6: São Paulo (SP); 7: Santa Catarina (SC)] and in geographical regions of MG [(maps at the bottom and right) (1: Vale do Rio Doce; 2: Triângulo Mineiro/Alto Paranaíba; 3: metropolitana de Belo Horizonte; 4: oeste; 5: Campo das Vertentes; 6: Zona da Mata; 7: sul/sudoeste)]. Spoligotype patterns, MIRU-VNTR types and numbers of isolates tested are presented at the lower left part of the figure. Asterisk indicates one or two isolates from animals without information on origin.
Only two isolates, one with MIRU type V10 (SB0295) and another with type V6 (SB1136), could not be clustered under our stringency definitions.

\section{DISCUSSION}

Brazil has the largest commercial cattle herd in the world with 185.1 million animals in 2010 and $1.5 \%$ growth recorded in 2009. This growth can be explained by several factors, such as a reduction in production costs as a result of extensive farming, the availability of land with attractive prices for production and the use and incorporation of research results and technologies to improve product quality and competitiveness (IBGE 2009). However, infectious diseases such as bovine TB have caused great economic losses in national livestock, reducing production rates nationwide.

After its introduction in 2001, the PNCEBT has sought the use of more effective methods to control bovine TB. The recent development of genotyping procedures that are capable of recognising many microorganisms at the strain level has improved the understanding of the transmission of infectious diseases (Struelens \& ESGEM 1996). In the present study, we applied two molecular fingerprinting methods, spoligotyping and MIRU-VNTR typing, to assess the genotypic diversity of Brazilian strains of $M$. bovis and to better understand bovine TB transmission in Brazil. Previous studies already demonstrated the efficiency of both methods in several countries (Sola et al. 2003, Boniotti et al. 2009, Duarte et al. 2010). In Brazil, however, IS6110-RFLP, polymorphic guanine-cytosine-rich sequence-RFLP and spoligotyping, but not MIRU-VNTR typing, have been

\section{TABLE II}

Frequency and genotypic profiles of mycobacterial interspersed repetitive unit-variable number tandem repeats (MIRU-VNTR) types

\begin{tabular}{lcc}
\hline ID & $\begin{array}{c}\text { Isolates } \\
\mathrm{n}(\%)\end{array}$ & $\begin{array}{c}\text { MIRU-VNTR } \\
\text { genotypes }\end{array}$ \\
\hline V1 & $3(4.9)$ & 132224253322 \\
V2 & $7(11.4)$ & 232224233322 \\
V3 & $2(3.3)$ & 232224263322 \\
V4 & $14(23)$ & 232324233322 \\
V5 & $6(9.8)$ & 232324243322 \\
V6 & $4(6.6)$ & 232324252422 \\
V7 & $15(24.6)$ & 232324253322 \\
V8 & $2(3.3)$ & 232424233322 \\
V9 & $1(1.6)$ & 232224153322 \\
V10 & $1(1.6)$ & 232224233522 \\
V11 & $1(1.6)$ & 232224253322 \\
V12 & $1(1.6)$ & 232324113322 \\
V13 & $1(1.6)$ & 232324233321 \\
V14 & $1(1.6)$ & 232324252322 \\
V15 & $1(1.6)$ & 232324253321 \\
V16 & $1(1.6)$ & 242324263322 \\
\hline
\end{tabular}


reported as typing methods for $M$. bovis isolates (Zanini et al. 2001, 2005, Rodriguez et al. 2004). The approach used in this study for the genetic analysis of $M$. bovis isolates, combining spoligotyping and VNTR analysis, is still limited in Latin America.

In the present study, all 17 identified spoligotype patterns had deletions at spacers 3, 9, 16 and 39-43, which is typical for M. bovis. Table VI compares the frequencies of the main spoligotypes observed in this study with those reported in earlier studies in Brazil and other countries. The less frequent spoligotypes SB0134, SB1055, SB1145 and SB1802 were only observed in two isolates each (3.3\%). Type SB0134 has been reported in France (Zanella et al. 2008, Haddad et al. 2001), Spain

\section{TABLE III}

Number of occurrences of individual mycobacterial interspersed repeptitive unit-variable number tandem repeats alleles and allelic diversity for each locus

\begin{tabular}{|c|c|c|c|c|c|c|c|}
\hline \multirow[b]{2}{*}{ Locus } & \multicolumn{6}{|c|}{ Allele number } & \multirow{2}{*}{$\begin{array}{l}\text { Allelic } \\
\text { diversity }\end{array}$} \\
\hline & 1 & 2 & 3 & 4 & 5 & 6 & \\
\hline MIRU 2 & 3 & 58 & & & & & 0.10 \\
\hline MIRU 4 & & & 60 & 1 & & & 0.03 \\
\hline MIRU10 & & 61 & & & & & 0.00 \\
\hline MIRU 16 & & 15 & 44 & 2 & & & 0.43 \\
\hline MIRU 20 & & 61 & & & & & 0.00 \\
\hline MIRU 23 & & & & 61 & & & 0.00 \\
\hline MIRU 24 & 2 & 59 & & & & & 0.06 \\
\hline MIRU 26 & 1 & & 25 & 6 & 26 & 3 & 0.65 \\
\hline MIRU 27 & & 5 & 56 & & & & 0.15 \\
\hline MIRU 31 & & & 56 & 4 & 1 & & 0.16 \\
\hline MIRU 39 & & 61 & & & & & 0.00 \\
\hline MIRU 40 & 2 & 59 & & & & & 0.06 \\
\hline
\end{tabular}

(Rodríguez et al. 2010), Italy (Serraino et al. 1999), mainland Great Britain (Hewinson et al. 2006) and in Brazil (Viana-Niero et al. 2006). Type SB1055 has been observed in Argentina, Paraguay, Uruguay, Mexico, Costa Rica and Brazil. Both SB1145 and SB1802 have only been isolated in Brazil (Mbovis.org). The rest of the spoligotypes characterised in our study have been previously isolated in the Netherlands (SB0332, SB0337) (Mbovis.org), Australia (SB1033) (Cousins et al. 1998), the United Kingdom (SB0267), Argentina (SB0484) and Brazil (SB1136, SB1803, SB1806) (Mbovis.org).

In this study, the most frequent spoligotype patterns were similar to the BCG strain (SB0120), only differing from the original strain by the loss of spacer 21 (SB0121) or spacers 21 and 37 (SB0295). Other spoligotypes observed in this study shared the same features as spoligotype SB0140, diverging from the precursor strain by the absence of spacer 36 (SB0274), spacer 34 (SB1033), or spacers 1, 2 (SB0484). Haddad et al. (2004) suggested the existence of two dominant groups of spoligotypes. The first group is the BCG-like group, represented by its BCG-like ancestor (SB0120) and SB0121, which has a high frequency in countries such as France, Italy, Belgium, Spain and Portugal, as well as in countries that are heavily involved in trading cattle with these countries. The other group, the GB09 group (SB0140), has dominant types in England. According to this theory, the ancestor types either became the dominant pattern in countries where they were introduced or evolved into new but similar spoligotypes. Our data confirm the co-existence of isolates of the BCG-like group (SB0120) and the GB09 group (SB0140) in Brazil. However, the first group was more prevalent.

Corroborating our findings, Smith et al. (2011) identified a new clonal complex of $M$. bovis named European 1 (Eu1), characterized by the deletion of the chromosomal region of difference RD17 or RDEu1, marked by the loss of spoligotype spacer 11 and represented by SB0140 as the most common spoligotype pattern associated with this clonal complex. According to the authors, this clonal complex is observed at a low frequency in Brazil, but is dominant in neighbouring South American countries.

TABLE IV

Comparison of discriminatory power of spoligotyping, mycobacterial interspersed repetitive unit-variable number tandem repeats (MIRU-VNTR) typing and combined methods

Typing methods

\begin{tabular}{lccc} 
& & & Spoligotyping \\
& & & + \\
Variables & Spoligotyping & MIRU-VNTR & MIRU-VNTR \\
\hline Patterns (total) (n) & 17 & 16 & 29 \\
Individual types (n) & 8 & 8 & 18 \\
Clusters (n) & 9 & 8 & 11 \\
Size of clusters (n) & $2-18$ & $2-15$ & $2-9$ \\
Clustered isolates [n (\%)] & $53(86.9)$ & $53(86.9)$ & $43(70.5)$ \\
Discriminatory index (h) & 0.85 & 0.86 & 0.94 \\
\hline
\end{tabular}


TABLE V

Comparison of discriminatory power of spoligotyping and mycobacterial interspersed repetitive unit-variable number tandem repeats (MIRU-VNTR) typing in 61 Mycobacterium bovis isolates

Resolution of spoligotypes by MIRU-VNTR
Resolution of MIRU-VNTR types by spoligotyping

\begin{tabular}{|c|c|c|c|}
\hline $\begin{array}{l}\text { Spoligotype } \\
\text { patterns }(n)\end{array}$ & MIRU-VNTR types (n) & $\begin{array}{l}\text { MIRU-VNTR } \\
\text { types (n) }\end{array}$ & $\begin{array}{l}\text { Spoligotype } \\
\text { patterns (n) }\end{array}$ \\
\hline S1 (3) & V2 (1), V7 (1), V13 (1) & V $1(3)$ & $\mathrm{S} 3(3)$ \\
\hline S2 (14) & V8 (2), V4 (3), V14 (1), V7 (8) & V 2 (7) & S1 (1), S3 (1), S5 (5) \\
\hline $\mathrm{S} 3(18)$ & V1 (3), V2 (1), V6 (1), V7 (3), V4 (9), V10 (1) & V 3 (2) & S6 (2) \\
\hline S4 (4) & V5 (4) & V 4 (14) & S2 (3), S3 (9), S11 (1), S14 (1) \\
\hline S5 (6) & V2 (5), V9 (1) & V5 (6) & S4 (4), S9 (1), S10 (1) \\
\hline S6 (2) & V3 (2) & V6 (4) & S3 (1), S7 (2), S17 (1) \\
\hline S7 (2) & V6 (2) & V $7(15)$ & $\mathrm{S} 1$ (1), S2 (8), S3 (3), S8 (2), S12 (1) \\
\hline S8 (2) & V7 (2) & V 8 (2) & $\mathrm{S} 2(2)$ \\
\hline S9 (2) & V5 (1), V11 (1), & - & - \\
\hline S10-S17 (8) & $\begin{array}{l}\text { V4 (2), V5 (1), V6 (1), V7 (1), } \\
\text { V12 (1), V15 (1), V16 (1) }\end{array}$ & V9-V16 (8) & $\begin{array}{c}\mathrm{S} 1 \text { (1), S2 (1), S3 (1), S5 (1), S9 (1), } \\
\text { S13 (1), S15 (1), S16 (1) }\end{array}$ \\
\hline
\end{tabular}

TABLE VI

Comparison of frequency of the most common spoligotypes observed in this study and in other reports

\begin{tabular}{|c|c|c|c|c|}
\hline \multirow[b]{2}{*}{ Spoligotype pattern } & \multicolumn{2}{|c|}{ Frequency (\%) } & \multirow[b]{2}{*}{ Country } & \multirow[b]{2}{*}{ Report } \\
\hline & This study & Other studies & & \\
\hline SB0295 & 29.5 & $\begin{array}{c}41.7 \\
25.6 \\
6.2 \\
4.3\end{array}$ & $\begin{array}{l}\text { Brazil } \\
\text { Brazil } \\
\text { Portugal } \\
\text { Spain }\end{array}$ & $\begin{array}{l}\text { Zanini et al. (2005) } \\
\text { Rodriguez et al. (2004) } \\
\text { Duarte et al. (2008) } \\
\text { Rodríguez et al. (2010) }\end{array}$ \\
\hline SB0121 & 23 & $\begin{array}{c}46 \\
29.5 \\
26.7 \\
25.6 \\
9.8 \\
3 \\
2.8 \\
1.1\end{array}$ & $\begin{array}{c}\text { Spain } \\
\text { Spain } \\
\text { Portugal } \\
\text { Brazil } \\
\text { France } \\
\text { South Africa } \\
\text { Brazil } \\
\text { Italy }\end{array}$ & $\begin{array}{l}\text { Aranaz et al. (1996) } \\
\text { Rodríguez et al. (2010) } \\
\text { Duarte et al. (2008) } \\
\text { Rodriguez et al. (2004) } \\
\text { Haddad et al. (2001) } \\
\text { Michel et al. (2008) } \\
\text { Zanini et al. (2005) } \\
\text { Boniotti et al. (2009) }\end{array}$ \\
\hline SB0274 & 9.8 & $\begin{array}{l}13 \\
2.8 \\
<1\end{array}$ & $\begin{array}{c}\text { Mainland GB } \\
\text { Brazil } \\
\text { France }\end{array}$ & $\begin{array}{l}\text { Hewinson et al. (2006) } \\
\text { Zanini et al. (2005) } \\
\text { Haddad et al. (2001) }\end{array}$ \\
\hline SB0881 & 6.6 & $\begin{array}{l}6.12 \\
<1 \\
<1\end{array}$ & $\begin{array}{l}\text { Brazil } \\
\text { France } \\
\text { Spain }\end{array}$ & $\begin{array}{l}\text { Viana-Niero et al. (2006) } \\
\text { Haddad et al. (2001) } \\
\text { Rodríguez et al. (2010) }\end{array}$ \\
\hline SB0120 & 4.9 & $\begin{array}{c}26.7 \\
26.2 \\
22.2 \\
14.3 \\
10.8 \\
4.6 \\
4.3 \\
2 \\
1.1\end{array}$ & $\begin{array}{c}\text { France } \\
\text { Italy } \\
\text { Brazil } \\
\text { Brazil } \\
\text { Spain } \\
\text { Brazil } \\
\text { Spain } \\
\text { South Africa } \\
\text { Portugal }\end{array}$ & $\begin{array}{l}\text { Haddad et al. (2001) } \\
\text { Boniotti et al. (2009) } \\
\text { Zanini et al. (2005) } \\
\text { Zanini et al. (2001) } \\
\text { Aranaz et al. (1996) } \\
\text { Rodriguez et al. (2004) } \\
\text { Rodríguez et al. (2010) } \\
\text { Michel et al. (2008) } \\
\text { Duarte et al. (2008) }\end{array}$ \\
\hline
\end{tabular}


Therefore, strains from Brazil should be derived from the BCG-like spoligotype patterns. According to Feldman (1955), bovine TB was introduced into Brazil with cattle imported from Europe during the colonisation of Brazil in the early 16th century. This activity intensified from 1920-1930. In addition, tuberculin testing was not introduced until 1937 and therefore, prior to that, infected animals could freely transmit bovine TB (Feldman 1955). Nevertheless, a more detailed genotyping study on a representative number of isolates from all Brazilian states would better reveal the population structure of $M$. bovis strains in Brazil, reflecting how they spread.

The 12-MIRU-VNTR loci differentiated $61 \mathrm{M}$. bovis strains into 16 distinct types and unexpectedly, using 12 MIRU loci for this typing procedure resulted in the clustering of 53 of the 61 isolates $(86.9 \%)$, producing the same grouping level as that of spoligotyping. However, the number of isolates in the defined clusters by spoligotyping was reduced by MIRU-VNTR typing (from 2-18 to 2-15).

In this study, only MIRU loci 16 and 26 showed considerable discriminatory power and a total absence of allelic diversity was observed for MIRU loci 10, 20, 23 and 39. This finding is in agreement with previously published data showing that MIRU locus 26 is the most discriminatory locus for $M$. bovis, while loci 2, 4, 10, 20, $23,24,27,31,39$ and 40 are less or not at all discriminatory (Roring et al. 2004). Contrary to these findings and other reports, some studies observed little allelic diversity for MIRU locus 16 (Roring et al. 2004, Boniotti et al. 2009, Duarte et al. 2010). In addition, Hilty et al. (2005) found a moderate level of allelic polymorphism for MIRU loci 4 and 27 and Allix et al. (2006) reported high allelic diversity for MIRU loci 24 and 27.

In our study, MIRU loci 2, 27 and 31 were involved in a single (MIRU loci 2 and 27) or two-loci variation (MIRU locus 31), i.e., were able to discriminate some isolates from other closely related isolates based on variations of one or two alleles in their respective loci. Thus, along with MIRU loci 16 and 26, these three loci were added to the minimal subset of loci capable of discriminating between $87.5 \%$ (14 of 16 types) of the genotypes assigned to $M$. bovis isolates.

Many reports on the MIRU-VNTR genotyping of M. bovis isolates tested other sets of tandem repeat loci, such as the ETRs (ETR A-F) (Frothingham \& MeekerO'Connell 1998) or the Queen's University Belfast VNTRs (Skuce et al. 2002), demonstrating an increasing discriminatory power in the case of $M$. bovis isolates, either epidemiologically related or not (Roring et al. 2002, Allix et al. 2006, Boniotti et al. 2009, Duarte et al. 2010). According to Roring et al. (2004), although some individual loci have a high discriminatory power for both M. tuberculosis and M. bovis isolates, others seem to be more polymorphic for a particular species and thus, in general, fewer polymorphisms are observed in $M$. bovis isolates. In addition, regional differences in the discriminatory power of genetic markers make it necessary to define an optimal combination of genotyping markers to

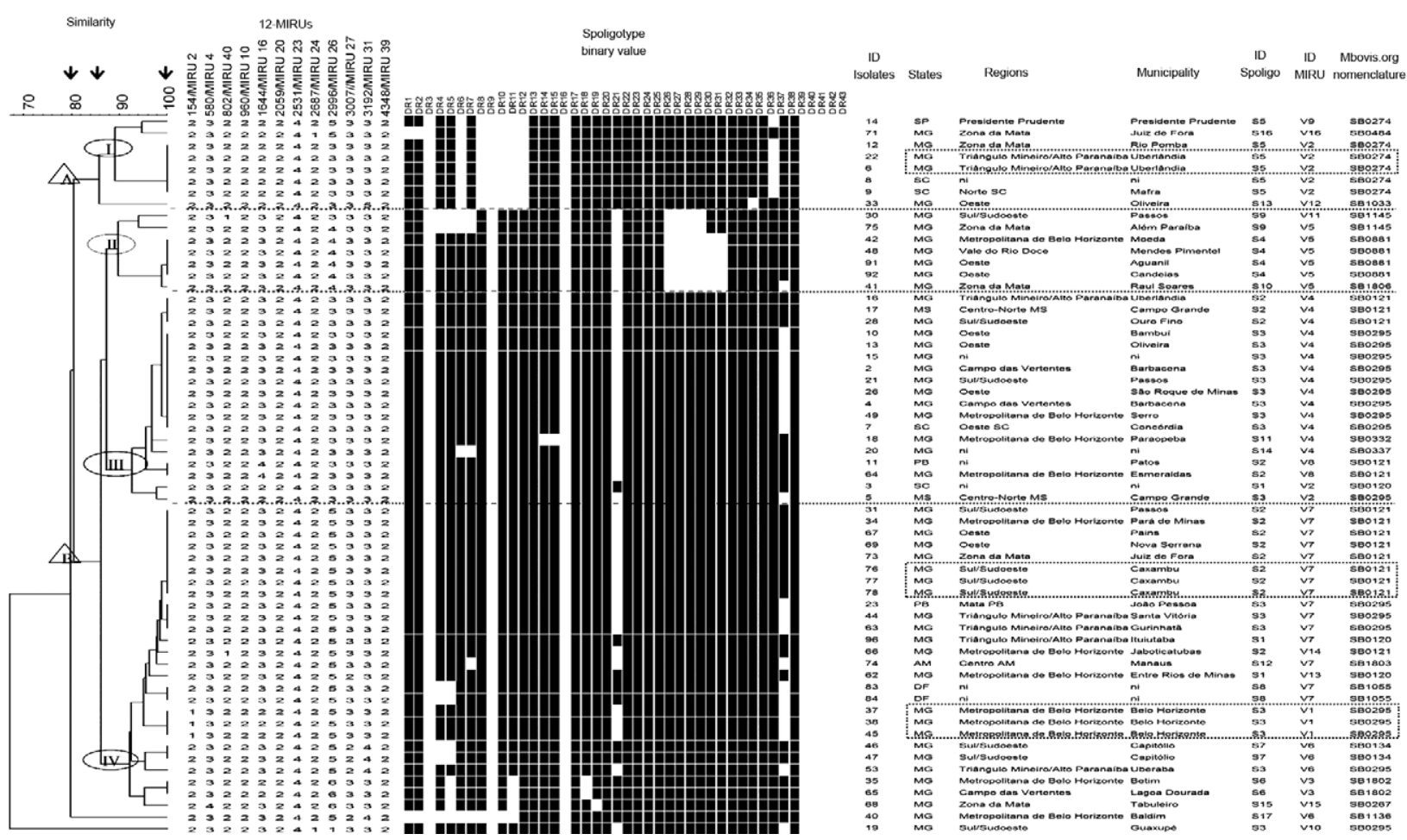

Fig. 2: the dendrogram was constructed based on simultaneous analysis of spoligotypes and MIRU-VNTR genotypes using the categorical index and unweighted pair-grouping method analysis algorithm. Arrows indicate the similarity indices evaluated. Ellipses and triangles demarcate groups formed by the cut-offs $85 \%$ and $80 \%$, respectively. Dashed squares designate isolates with possible epidemiological links. 
be used in a particular region or country (Roring et al. 2004, Hilty et al. 2005). Therefore, we suggest that only a few loci (including MIRUs 16 and 26) from the 12MIRU-VNTR should be used to create a proper subset of loci to genotype Brazilian M. bovis isolates. Currently, we are analysing the $h$ values of more loci to add them to the presently defined panel.

The spoligotyping $\mathrm{h}$ value (0.85) in our study was similar to that found by Allix et al. (2006) and Rodríguez et al. (2010) and higher than that obtained by Roring et al. (2004), Hilty et al. (2005) and Michel et al. (2008). An almost identical h was attained for 12MIRU-VNTR typing (0.86), but the combined analysis resulted in an h value of 0.94 , confirming their value in genotyping $M$. bovis isolates (Frothingham \& MeekerO’Connell 1998, Sola et al. 2003).

A final cluster analysis was performed on the genotypes, considering both the DR region and MIRUs and the number of clustered strains, and the cluster sizes were highly dependent on the stringency used to define the clusters. Using $100 \%$ similarity as the definition for clustering, we observed 29 different genotypes from 61 isolates and both methods were congruent, keeping isolates with possible epidemiological links grouped (dashed squares in the dendrogram) and keeping isolates characterised as unique types ungrouped in both tests. According to Smith et al. (2006), this congruence observed between spoligotyping and MIRU-VNTR typing is consistent with the clonal population structure of M. bovis.

When using a stringency value of $85 \%$ similarity to define clusters, we observed four principal groups (Fig. 2). The first group was comprised of isolates from specimens collected in the southeast and south of the country. This cluster was composed of spoligotypes that had been previously isolated in countries such as Argentina (SB0484) and Australia (SB1033), which have close relationships with Britain (Cousins et al. 1998, Zumárraga et al. 1999), with most of the isolates genotyped as GB09 (SB0140) (Haddad et al. 2004). Type SB0274, which is close to this ancestral genotype, was first isolated in British territory (UK) (Haddad et al. 2001) and Smith et al. (2011) suggested that the UK was the distribution centre of the Eul clonal complex, which is best represented by the SB0140 spoligotype. Group II clustered spoligotypes that were characterised from isolates obtained only in MG with two spoligotypes identified in Brazil (SB1145, SB1806). Isolates from MG, MS and SC were grouped into cluster III, with a strong representation of spoligotypes belonging to the BCGlike group (SB0120). The last cluster (IV) was represented by isolates from the southeastern (MG), northern $(\mathrm{AM})$, northeastern (PB) and centre-west (DF) regions of Brazil. Spoligotypes of this cluster have previously been characterised in Continental European countries. One spoligotype, SB0134, had previously been isolated in countries of the Americas. The spoligotypes SB1802 and SB1803, thus far only identified in Brazil, were also grouped in this cluster (Mbovis.org).

Finally, using $80 \%$ similarity to define clusters, we observed two main clusters (Fig. 2) that were subdivided by ancestors of the GB09 (SB0140) and BCG-like groups. This result confirms our first statement on the coexistence of spoligotype patterns descending from these groups in our country. Cluster A had the same composition as that observed in group I, as defined with the higher stringency setting. The second cluster (B) was shared by genotypes that descended from the BCG-like spoligotype (SB0120), which is found worldwide, such as SB0121, SB0295 and others from countries such as France, Belgium, Spain, Netherlands, Italy and those closely linked to these countries. The SB1055 spoligotype has previously been recovered in Brazil, Argentina, Paraguay, Uruguay, Mexico and Costa Rica, and spoligotype pattern SB1145 has only been characterised by spoligotyping, until now, in Brazil (Mbovis.org).

In conclusion, our results reinforce the need to standardise methods with high discriminatory power that can effectively track $M$. bovis infections in Brazilian cattle herds. The methods used in this study to genotype $61 \mathrm{M}$. bovis isolates from Brazilian cattle herds produced a high discriminatory index. Currently, new VNTR loci are available to create several subseries with a high power of resolution. According to Sola et al. (2003), the combination of spoligotyping and MIRU-VNTR typing are still considered to have the best cost/output ratio in TB genotyping, a statement that has been confirmed by recent studies (Allix et al. 2006, Smith et al. 2006, Boniotti et al. 2009, Duarte et al. 2010). Therefore, we suggest using spoligotyping as an initial screening tool for $M$. bovis isolates and combining it with a more discriminatory method, such as VNTR typing, for more advanced analysis of the molecular epidemiology of bovine TB, e.g., for studies identifying risk factors for recently transmitted TB and to trace cattle within the country and between Brazil and other countries, thus increasing the effectiveness of control programs and disease eradication.

\section{REFERENCES}

Allix C, Walravens K, Saegerman C, Godfroid J, Supply P, FauvilleDufaux M 2006. Evaluation of the epidemiological relevance of variable-number tandem-repeat genotyping of Mycobacterium bovis and comparison of the method with IS6110 restriction fragment length polymorphism analysis and spoligotyping. J Clin Microbiol 44: 1951-1962.

Aranaz A, Liébana E, Mateos A, Domínguez L, Vidal D, Domingo M, Gonzolez O, Rodriguez-Ferri EF, Bunschoten AE, Van Embden JDA, Cousins D 1996. Spacer oligonucleotide typing of Mycobacterium bovis strains from cattle and other animals: a tool for studying epidemiology of tuberculosis. J Clin Microbiol 34: 2734-2740.

Boniotti MB, Goria M, Loda D, Garrone A, Benedetto A, Mondo A, Tisato E, Zanoni M, Zoppi S, Dondo A, Tagliabue S, Bonora S, Zanardi G, Pacciarini ML 2009. Molecular typing of Mycobacterium bovis strains isolated in Italy from 2000 to 2006 and evaluation of variable-number tandem repeats for geographically optimized genotyping. J Clin Microbiol 47: 636-644.

Cosivi O, Grange JM, Daborn CJ, Raviglione MC, Fujikura T, Cousins D, Robinson RA, Huchzermeyer HF, de Kantor I, Meslin FX 1998. Zoonotic tuberculosis due to Mycobacterium bovis in developing countries. Emerg Infect Dis 4: 59-70.

Cousins D, Williams S, Liébana E, Aranaz A, Bunschoten A, van Embden JDA, Ellis T 1998. Evaluation of four DNA typing techniques in epidemiological investigations of bovine tuberculosis. J Clin Microbiol 36: 168-178. 
Duarte EL, Domingos M, Amado A, Botelho A 2008. Spoligotype diversity of Mycobacterium bovis and Mycobacterium caprae animal isolates. Vet Microbiol 130: 415-421.

Duarte EL, Domingos M, Amado A, Cunha MV, Botelho A 2010. MIRU-VNTR typing adds discriminatory value to groups of $M y$ cobacterium bovis and Mycobacterium caprae strains defined by spoligotyping. Vet Microbiol 143: 299-306.

Feldman J 1955. Tuberculose humana de origem bovina: contribuição ao seu estudo no estado de Minas Gerais, PhD Thesis, Universidade Federal de Minas Gerais/Escola de Medicina Veterinária, Belo Horizonte, 260 pp.

Frothingham R, Meeker-O'Connell WA 1998. Genetic diversity in the Mycobacterium tuberculosis complex based on variable numbers of tandem DNA repeats. Microbiol 144: 1189-1196.

Haddad N, Ostyn A, Karoui C, Masselot M, Threl MF, Hughes SL, Inwald J, Hewinson RG, Durand B 2001. Spoligotype diversity of Mycobacterium bovis strains isolated in France from 1979 to 2000. J Clin Microbiol 39: 3623-3632.

Haddad N, Masselot M, Durand B 2004. Molecular differentiation of Mycobacterium bovis isolates. Review of main techniques and applications. Res Vet Sc 76: 1-18.

Hewinson RG, Vordermeier HM, Smith NH, Gordon SV 2006. Recent advances in our knowledge of Mycobacterium bovis: a feeling for the organism. Vet Microbiol 112: 127-139.

Hilty M, Digimbaye C, Schelling E, Baggi F, Tanner M, Zinsstag J 2005. Evaluation of the discriminatory power of variable number of tandem repeat (VNTR) typing of Mycobacterium bovis strains. Vet Microbiol 109: 217-222.

Hunter PR, Gaston MA 1988. Numerical index of the discriminatory ability of typing systems: an application of Simpson's index of diversity. J Clin Microbiol 26: 2465-2466.

IBGE - Instituto Brasileiro de Geografia e Estatística 2009. [home page on the internet]. Rio de Janeiro: produção da pecuária municipal 2009. Available from: ibge.gov.br/english/estatistica/ economia/ppm/2009/ppm2009.pdf.

Kamerbeek J, Schouls L, Kolk A, Agterveld M, Soolingen D, Kuijper S, Bunschoten A, Molhuizen H, Shaw R, Goyal M, van Embden J 1997. Simultaneous detection and strain differentiation of $M y$ cobacterium tuberculosis for diagnosis and epidemiology. J Clin Microbiol 35: 907-914.

MAPA - Ministério da Agricultura, Pecuária e Abastecimento, Brasil 2006. Programa nacional de controle e erradicação da brucelose e da tuberculose animal (PNCEBT), MAPA/SDA/ DSA, Brasília, 188 pp.

Michel AL, Hlokwe TM, Coetzee ML, Mare L, Connoway L, Rutten VPMG, Kremer K 2008. High Mycobacterium bovis genetic diversity in a low prevalence setting. Vet Microbiol 126: 151-159.

Michel AL, Müller B, van Helden PD 2010. Mycobacterium bovis at the animal-human interface: a problem, or not? Vet Microbiol 140: $371-381$

Mota PMPC 1985. Estudo da esofagostomose como fator predisponente de reações alérgicas inespecíficas da tuberculose bovina, MSc Thesis, Universidade Federal de Minas Gerais, Belo Horizonte, $70 \mathrm{pp}$

Mota PMPC, Lobato FCF 1998. Tuberculose bovina: uma revisão. In AP Lage, FCF Lobato, PMPC Mota, VSP Gonçalves, Atualização em tuberculose bovina, FEP-MVZ, Belo Horizonte, p. 3-34.

OIE - World Organization for Animal Health 2010. World Animal Health Information Database - WAHID Interface (database on the Internet). Disease Timelines (cited 2011 Mar 14). Available from: web.oie.int/wahis/public.php?page=disease timelines.
Pitcher DG, Saunders NA, Owen RJ 1989. Rapid extraction of bacterial genomic DNA with guanidine thiocyanate. Lett Appl Microbiol 8: 151-156.

Rodriguez CAR, Zumárraga MJ, Oliveira EMD, Cataldi AA, Romano MI, Otto HH, Bonafé VL, Ferreira-Neto JS 2004. Caracterização molecular de isolados de Mycobacterium bovis do estado de São Paulo Brasil, utilizando a técnica de spoligotyping. Arq Inst Biol 71: 277-282.

Rodríguez S, Romero B, Bezos J, de Juan L, Alvarez J, Castellanos E, Moya N, Lozano F, González S, Sáez-Llorente JL, Mateos A, Domínguez L, Aranaz A 2010. High spoligotype diversity within a Mycobacterium bovis population: clues to understanding the demography of the pathogen in Europe. Vet Microbiol 141: 89-95.

Roring S, Scott AN, Brittain D, Walker I, Hewinson RG, Neill SD, Skuce RA 2002. Development of variable-number tandem repeat typing of Mycobacterium bovis: comparison of results with those obtained by using exact tandem repeats and spoligotyping. J Clin Microbiol 40: 2126-2133.

Roring S, Scott AN, Hewinson RG, Neill SD, Skuce RA 2004. Evaluation of variable number tandem repeat (VNTR) loci in molecular of Mycobacterium bovis isolates from Ireland. Vet Microbiol 101: 65-73.

Serraino A, Marchetti G, Sanguinetti V, Rossi MC, Zanoni RG, Catozzi L, Bandera A, Dini W, Mignone W, Franzetti F, Gori A 1999. Monitoring of transmission of tuberculosis between wild boars and cattle: genotypical analysis of strains by molecular epidemiology techniques. J Clin Microbiol 37: 2766-2771.

Skuce RA, McCorry TP, MacCarroll JF, Rorign SMM, Scott AN, Brittain D, Hughes SL, Hewinson RG, Neill SD 2002. Discrimination of Mycobacterium tuberculosis complex bacteria using novel VNTR-PCR targets. Microbiology 148: 519-528.

Smith NH, Berg S, Dale J, Allen A, Rodriguez S, Romero B, Matos F, Ghebremichael S, Karoui C, Donati C, Machado AD, Mucavele C, Kazwala RR, Hilty M, Cadmus S, Ngandolo BN, Habtamu M, Oloya J, Muller A, Milian-Suazo F, Andrievskaia O, Projahn M, Barandiaran S, Macias A, Muller B, Zanini MS, Ikuta CY, Rodriguez CA, Pinheiro SR, Figueroa A, Cho SN, Mosavari N, Chuang PC, Jou R, Zinsstag J, van Soolingen D, Costello E, Aseffa A, Proano-Perez F, Portaels F, Rigouts L, Cataldi AA, Collins DM, Boschiroli ML, Hewinson RG, Neto JS, Surujballi O, Tadyon K, Botelho A, Zarraga AM, Buller N, Skuce R, Michel A, Aranaz A, Gordon SV, Jeon BY, Kallenius G, Niemann S, Boniotti MB, van Helden PD, Harris B, Zumárraga MJ, Kremer K 2011. European 1: a globally important clonal complex of Mycobacterium bovis. Infect Genet Evol 11: 1340-1351.

Smith NH, Gordon SV, de la Rua-Domenech R, Clifton-Hadley RS, Hewinson RG 2006. Bottlenecks and broomsticks: the molecular evolution of Mycobacterium bovis. Nat Rev Microbiol 4: 670-681.

Smith NH, Upton P 2011. Naming spoligotype patterns for the RD9deleted lineage of the Mycobacterium tuberculosis complex. Infect Genet Evol doi:10.1016/jmeegid.2011.08.002.

Sola C, Filliol IF, Legrand E, Lesjean S, Locht C, Supply P, Rastogi N 2003. Genotyping of the Mycobacterium tuberculosis complex using MIRU-VNTR's: association with VNTR and spoligotyping for molecular epidemiology and evolutionary genetics. Infect Genet Evol 3: 125-133.

Struelens MJ, the European Study Group on Epidemiological Markers (ESGEM) of the European Society for Clinical Microbiology and Infectious Diseases (ESCMID) 1996. Consensus guidelines for appropriate use and evaluation of microbial epidemiologic typing systems. Clin Microbiol Infect 2: 2-11. 
Supply P, Mazars E, Lesjean S, Vincent V, Gicquel B, Locht C 2000. Variable human minisatellite-like regions in the Mycobacterium tuberculosis. Mol Microbiol 36: 762-771.

Viana-Niero C, Rodriguez CA, Bigi F, Zanini MS, Ferreira-Neto JS, Cataldi A, Leao SC 2006. Identification of an IS6110 insertion site in plcD, the unique phospholipase $\mathrm{C}$ gene of Mycobacterium bovis. J Med Microbiol 5: 451-457.

Wayne LG, Engbaek HC, Engel HWB, Froman S, Gross W, Hawkins J, Kippler W, Karlson AG, Kleeberg HH, Krasnow I, Kubica GP, McDurmont C, Nel EE, Pattyn SR, Schroder KH, Showalter S, Tarnok I, Tsukamura M, Vergmann B, Wolinsky E 1974. Highly reproducible techniques for use in systematic bacteriology in the genus Mycobacterium: tests for pigment, urease, resistance to sodium chloride, hydrolysis of Tween 80 and P-galactosidase. Int $J$ Syst Bacteriol 24: 412-419.

Wayne LG, Engel HWB, Grassi C, Gross W, Hawkins J, Jenkins PA, Kappler W, Kleeberg HH, Krasnow I, Nel EE, Pattyn SR, Richards PA, Showalter S, Slosarek M, Szabo I, Tarnok I, Tsukamura M, Vergmann B, Wolinsky E 1976. Highly reproducible techniques for use in systematic bacteriology in the genus Mycobacterium: tests for niacin and catalase and for resistance to isoni- azid, thiophene-2-carboxylic acid hydrazide, hydroxylamine and p-nitrobenzoate. Int J Syst Bacteriol 26: 311-318.

Zanella G, Durand B, Hars J, Moutou F, Garin-Bastuji B, Duvauchelle A, Ferme M, Karoui C, Boschiroli ML 2008. Mycobacterium bovis in wildlife in France. $J$ Wildl Dis 44: 99-108.

Zanini MS, Moreira EC, Lopes MTP, Oliveira RS, Leão SC, Fioravant RL, Roxo E, Zumárraga M, Romano MI, Cataldi A, Salas, CE 2001. Mycobacterium bovis: polymerase chain reaction identification in bovine lymphonode biopsies and genotyping in isolates from Southeast Brazil by spoligotyping and restriction fragment length polymorphism. Mem Inst Oswaldo Cruz 96: 809-813.

Zanini MS, Moreira EC, Salas CE, Lopes MTP, Barouni AS, Roxo E, Telles MA, Zumárraga MJ 2005. Molecular typing of Mycobacterium bovis isolates from South-east Brazil by spoligotyping and RFLP. $J$ Vet Med B 52: 129-133.

Zumárraga MJ, Martin C, Samper S, Alito A, Latini O, Bigi F, Roxo E, Cicuta ME, Errico F, Ramos MC, Cataldi A, van Soolingen D, Romano MI 1999. Usefulness of spoligotyping in molecular epidemiology of Mycobacterium bovis - related infections in South America. J Clin Microbiol 37: 296-303. 